\title{
Crise do capital e desmonte da Seguridade Social: desafios (im)postos ao Serviço Social
}

\author{
Capital crisis and Social Security dismantling: \\ challenges (im)posed to Social Work
}

\begin{abstract}
Daniela Ribeiro Castilho
Assistente social, doutora em Serviço Social (UFRJ) e professora da Faculdade de Serviço Social (UFPA); pesquisadora do Grupo de Estudos e Pesquisa sobre Trabalho, Estado e Sociedade na Amazônia/PPGSS-UFPA — Belém/PA, Brasil.

danicastilho@ufpa.br
\end{abstract}

\section{Esther Luíza de Souza Lemos}

Assistente social, doutora em Serviço Social (UFRJ), professora do Curso de Serviço Social da Universidade Estadual do Oeste do Paraná (Unioeste) — Toledo/PR, Brasil, pesquisadora do Grupo de Pesquisa em Seguridade Social e Trabalho — Gesst (2015-6/UnB).

estherlemos@gmail.com

\begin{abstract}
Vera Lúcia Batista Gomes
Instituto de Ciências Sociais Aplicadas — Icsa/Faculdade de Serviço Social— Fass/Programa de Pós-Graduação em Serviço Social — PPGSS/Ufpa. Belém/PA, Brasil.

veragomesbelem@hotmail.com
\end{abstract}

Resumo: O presente artigo propõe a reflexão crítica sobre a crise do capital, suas inflexões no mundo do trabalho na conjuntura brasileira e os impactos na regressão de direitos. Analisa as contrarreformas implementadas a partir da década de 1990 e os sucessivos desmontes desferidos contra a política de Seguridade Social. A partir da perspectiva do projeto ético-político profissional, problematiza os desafios postos aos(às) assistentes sociais enquanto parte constitutiva da classe trabalhadora.

Palavras-chave: Direitos sociais. Seguridade Social. Serviço Social.
Abstract: This article proposes a critical reflection on the capital crisis, its inflections in labour's world, in the Brazilian conjuncture and impacts on the regression of rights. It analyzes the counter-reforms implemented since 1990s and the successive dismantling process of Social Security Policy. From the perspective of the professional ethical-political project, it problematizes the challenges before social workers as a constituent part of the working class.

Keywords: Social rights. Social Security. Social Work. 


\section{Introdução}

$\mathrm{N}$ o último ano, conquistas históricas da classe trabalhadora no Brasil têm sido derrotadas com uma velocidade inimaginável! A realidade histórica evidencia que as mesmas foram gestadas anteriormente e encontraram solo fértil no governo ilegítimo de Temer para serem implementadas diante de um processo de arrefecimento, pulverização e retrocesso na consciência da classe trabalhadora e de seus instrumentos organizativos.

O presente texto, a partir da análise da totalidade expressa na crise do capital e suas inflexões no mundo do trabalho, apreende a particularidade da conjuntura política nos governos Lula, Dilma e Temer, abordando os impactos na política de Seguridade Social, espaço sócio-ocupacional da maioria dos(as) assistentes sociais no país. Nesse contexto, os(as) assistentes sociais, como parte da classe trabalhadora, têm o desafio de "remar na contracorrente, andar no contravento, alinhando forças que impulsionem mudanças nas rotas dos ventos e das marés na vida em sociedade" (Iamamoto, 1998, p. 141).

\section{Crise do capital, reestruturação produtiva e suas inflexões no mundo do trabalho: como beber dessa bebida amarga?}

Historicamente, o sistema capitalista entra em crises frequentes que provocam novos conflitos, trazendo à tona novos consensos que encontram sua ascendência na natureza antagônica inerente a esse modo de produção - o antagonismo entre "sugadores" da riqueza e produtores, presente em toda sociedade de classe e que se torna mais forte na "fina flor" capitalista, gerando uma determinada oposição de interesses, que "[...] faz com que as lutas que travam as classes antagônicas se constituam em verdadeiro motor da história [...]" (Montaño e Duriguetto, 2011, p. 113).

Segundo Alves (2013), presencia-se, hoje, sob o capitalismo global, uma crise estrutural de valorização do capital, o que pode ser compreendida pela teoria da lei tendencial da queda da taxa de média de lucro, conforme exposto por Marx, em seu livro III de O capital - Crítica da economia política. 
Segundo Alves (1996), as políticas neoliberais e as transformações produtivas, que ocorreram a partir dos anos 1970, expressam a necessidade intrínseca do capital de impor controle sobre o trabalho, de anular o potencial da classe trabalhadora em seu projeto histórico de superação do capital.

Na América Latina, a década de 1980 é considerada como perdida, na medida em que a mesma foi marcada por perdas econômicas ocorridas através de baixas no PIB, aceleração da inflação, estagnação da produção industrial, perda do poder de compra dos salários e do nível de empregos. No Brasil, em particular, ficou registrada uma perda econômica incomum em comparação aos cinquenta anos anteriores, em que se obtiveram boas médias de crescimento econômico.

Se nessas décadas, no plano econômico, o país encontrava-se mergulhado num contexto de estagnação, no plano sociopolítico a sociedade brasileira vivia o período de redemocratização, conduzindo a promulgação de uma nova Constituição, em 1988. Essa nova Carta Magna contou com a participação dos(as) trabalhadores(as), seja por meio dos partidos do centro-esquerda, seja por meio da pressão dos sindicatos e dos movimentos sociais, o que contribuiu para o aprimoramento da legislação referente aos direitos sociais e trabalhistas.

Contudo, os anos 1990 foram marcados por tendências paradoxais: pela primeira vez o país promulga a Carta Constitucional, em 1988, com princípios universalistas, estabelecendo uma ruptura com a concepção minimalista de cidadania imposta até então pelos governos populistas e antidemocráticos. A referida Carta estabelece o trabalho como um direito inalienável que deve ser garantido pelo Estado, assim como as demais políticas sociais. Nessa perspectiva, o direito ao trabalho aparece como um dos pilares de sustentação da ordem social da mencionada Constituição, o qual vem se tentando assegurar, mesmo diante de contínuos ataques do capital e das mudanças no padrão de organização do trabalho instituídos em consonância com as políticas macroeconômicas de estabilização econômica, impostas pelo FMI e demais organismos multilaterais. Essas políticas delimitaram a intervenção do Estado, provocando o acirramento da "questão social" em suas variadas expressões, dentre as quais o aumento do desemprego. 
A retomada da competitividade se constituiu em uma estratégia importante para garantir, política e ideologicamente, a extração dos superlucros, possível apenas por meio da queda dos custos dos fatores de produção. Sendo assim, foram importantes os ataques aos custos do trabalho, mesmos nos países onde jamais foram significativos, como foi o caso do Brasil, isto é, a tentativa de saída para a crise econômica aparece nos discursos políticos como uma questão de ordem natural. Nesse quadro, as relações trabalhistas foram flexibilizadas e a legislação trabalhista desregulamentada, tendo como consequência o enfraquecimento das organizações representativas dos(as) trabalhadores(as). ${ }^{1}$

Nessa perspectiva, ao Estado brasileiro "competia a tarefa de criar os mecanismos para implementar as mudanças necessárias para o enfrentamento da referida crise, mas abstendo-se da responsabilidade de criar políticas de proteção social aos(às) trabalhadores(as) e, fundamentalmente, eliminando as barreiras para tornar o trabalho menos oneroso para os empregadores com a redução dos encargos sociais" (Oliveira, 2012, p. 500).

Segundo Castelo (2010), no final dos anos 1990 e início dos anos 2000, houve uma mudança no contexto político sul-americano, em decorrência dos sinais de esgotamento do neoliberalismo no plano econômico, com a persistência dos desequilíbrios macroeconômicos, a redução dos direitos sociais e o aumento do desemprego estrutural e do pauperismo. Como exemplo, esse autor destaca a crise vivida pela Argentina em 2001. No plano político, salienta que os antigos dirigentes dos projetos neoliberais locais alinhados ao Consenso de Washington (Argentina, Bolívia, Equador e Peru) foram destituídos do poder, e novos governantes foram eleitos com maciço apoio popular, por meio de coalizações partidárias com posições antineoliberais (Venezuela, Brasil, Argentina, Bolívia, Equador e Paraguai): têm-se então, no continente, novas possibilidades de movimentos políticos e ideológicos contestatórios ao neoliberalismo (Castelo, 2012).

Diante do fracasso da postura onipresente do mercado sob orientação neoliberal, nas duas últimas décadas do século XX foram reelaboradas novas

1. Cabe registrar que em contexto tão adverso para a classe trabalhadora brasileira, no governo do presidente Luiz Inácio da Silva (Lula) tramitou um Projeto de Reforma Sindical e Trabalhista que expressava o objetivo de flexibilizar os direitos e precarizar ainda mais o trabalho, visando elevar lucros para o capital, sob o discurso da necessidade de modernização e da democratização das relações do trabalho via negociação coletiva. 
estratégias de dominação capitalista sem prejuízo do objetivo principal: expansão do capital com hegemonia política. Sob essa ótica, a retomada do discurso do desenvolvimento se pauta na premissa de que estava em curso uma retomada das reformas liberais, uma nova configuração do Estado e, por conseguinte, uma reorientação das políticas sociais baseadas em programas focalizados dirigidos exclusivamente para a população pobre.

Contudo, as propostas emanadas do chamado Pós-Consenso de Washington mantiveram os princípios do primeiro Consenso, complementando com medidas que reforçavam a capacidade institucional do Estado com ênfase nos princípios político-ideológicos de maior intervenção das expressões da "questão social" nos países periféricos. A partir dessa correção de rumo, os projetos neoliberais de "reforma" do Estado ganharam uma nova configuração.

No Brasil foram instituídas "reformas" baseadas no ideário neoliberal desde o governo Collor de Mello, tendo continuidade com Fernando Henrique Cardoso - FHC, através do projeto de Emenda Constitucional n. 173, cujo principal responsável foi o então ministro da Administração e Reforma do Estado (extinto Mare) Luiz Carlos Bresser-Pereira. A análise dos fundamentos da "reforma", no estudo Desenvolvimento e crise no Brasil, efetuado por Bresser-Pereira (1968), apresenta a necessidade de se "reformar" o Estado brasileiro e torná-lo um Estado social-liberal:

[...] social porque continuará a proteger os direitos sociais e a promover o desenvolvimento econômico; liberal, porque o fará usando mais os controles de mercado e menos os controles administrativos, porque realizará os seus serviços sociais e científicos principalmente por meio de organizações públicas não estatais competitivas, porque tornará os mercados de trabalho mais flexíveis, porque promoverá a capacitação de recursos humanos e de suas empresas para a inovação e a competição internacional. (Idem, p. 18)

Assim, Bresser-Pereira estabeleceu como componentes básicos da "reforma", entre outros: a redefinição do papel regulador do Estado através da desregulamentação; o aumento da capacidade política do Estado em intermediar interesses, através da privatização, terceirização e publicização que envolvem a criação de organizações sociais; o aumento da governança, ou seja, a recuperação 
da capacidade financeira e administrativa de implementar decisões políticas tomadas pelo governo, através de ajuste fiscal.

Behring (2003), ao analisar criticamente os principais pressupostos que estão presentes na reforma do Estado do ministro Bresser-Pereira, afirma que se trata de um "processo destrutivo não criador [...] uma contrarreforma do Estado brasileiro, que implicou um profundo retrocesso social em beneficio de poucos” (p. 171). Nessa perspectiva, o papel do Estado preconizava a estabilidade econômica e o desenvolvimento, associado à flexibilização e à descentralização das decisões, assim como à publicização que atinge diretamente as políticas públicas; em consequência, o Estado brasileiro aumentaria a sua "governance, resgatando o seu papel de indutor do desenvolvimento econômico e social e de garantia dos direitos de cidadania" (Idem, p. 183).

As referidas reformas preconizavam uma combinação de políticas econômicas direcionadas para o crescimento econômico sustentado e não inflacionado e de políticas sociais eficazes para a produção da equidade e do desenvolvimento humano. Contudo, tais políticas tinham por base uma brutal contenção de gastos do governo em todas as áreas, com a exceção do pagamento da dívida e de pessoal, o que, em síntese, significava: o sucateamento do setor público; a falência das políticas sociais universais implementadas pelo Estado pós-Constituição brasileira de 1988. Tais propostas ganham materialidade institucional por meio de políticas sociais assistencialistas e focalizadas de transferência de renda, programas de economia solidária e de empoderamento dos indivíduos e comunidades, bem como de medidas regulatórias do Estado diante das falhas do mercado (Ibidem).

\section{Os (des)governos Lula e Dilma: tanta mentira, tanta força bruta!}

O governo do presidente Lula seguiu o receituário de seu antecessor e do pós-Consenso de Washington, pois conjugava medidas de cunho social-liberal, sem romper com as estruturas neoliberais. Ao contrário, rendia-se às estratégias de valorização do capital, apoiando um conjunto de medidas para favorecer e proteger o investimento das transnacionais, em detrimento dos investimentos em Educação, Saúde, Habitação, entre outros (Castelo, 2010). 
Os governos petistas legitimaram a política econômica neoliberal de FHC, conferindo papel central à estabilidade monetária como requisito indispensável ao crescimento econômico estável. Para isso, mantiveram intactas sua política de ajuste fiscal e de juros altos, dando total liberdade de movimentação de capitais, ao mesmo tempo em que, como forma de compensação por sua opção em não fazer as reformas necessárias à distribuição da riqueza socialmente produzida, possibilitou o acesso aos programas sociais de uma parcela significativa da classe trabalhadora que se encontrava em situação de extrema pobreza (Iamamoto, 2008).

Tais programas sociais, em especial os de transferência de renda, tornam-se "decisivos" para responder à agudização das expressões da "questão social" e dão continuidade às ações assistencialistas, pulverizadas, fragmentadas e focalizadas, numa explícita perspectiva de "políticas pobres para pobres", que passam a ser atendidas não mais diretamente pelo Estado, mas sim, pelo chamado "terceiro setor", por meio de organizações e instituições privadas, num abrangente processo de privatização e mercantilização da política social que deveria ser dever do Estado, mas que sob a égide neoliberal passa a ser somente "fiscalizado e gerenciado", sendo sua execução terceirizada para a iniciativa privada. A implantação do SUAS a partir de 2005 tensiona essa tendência, obrigando o Estado a executar serviços diretamente através dos Centros de Referência de Assistência Social — CRAS e Centros de Referência Especializada de Assistência Social — CREAS.

A política implementada nos governos Lula e Dilma, sem confronto com o capital, atestou a inépcia e a inutilidade da proposta de natureza social-democrata travestida de "democrático-popular", de tentativa de refundar o papel político e social do Estado, considerando a frágil correlação de forças existente entre as camadas populares e a burguesia, fruto de vinte anos de ditadura militar; implantação do neoliberalismo e cooptação de parte significativa dos movimentos sociais, partidos e sindicatos.

O reformismo pelo alto do petismo, sob a designação de "neodesenvolvimentismo", foi à opção trágica e dramática desses governos diante da incapacidade de ir além da ordem capitalista, escolhendo e priorizando políticas que não alteram nenhum interesse firmado com a classe dominante, combinando, 
no limite da ordem neoliberal, um projeto que conjugue redistribuição de renda, incentivo ao consumo e enfrentamento à pobreza extrema, com os interesses do poder hegemônico oligárquico-burguês que se encontra presente nas esferas econômicas e políticas da cena contemporânea brasileira (Alves, 2014).

É importante salientar aqui que a opção pela continuidade da política econômica de seu antecessor, de garantir o pagamento dos juros e a amortização da dívida pública, impactou sobremaneira no orçamento destinado à Seguridade Social, principalmente por meio da continuação da Desvinculação das Receitas da União (DRU), que tinha como objetivo maior a garantia do superávit primário, como forma de manter recursos para o pagamento de uma dívida pública absolutamente questionável, como nos indica Fattorelli (2016).

E mais uma vez a Seguridade Social foi alvo de ataques, agora pelo petismo, que propôs uma "reforma" no sistema previdenciário, seguindo a cartilha neoliberal, que tinha como apelo maior o falso pretexto de déficit da Previdência Social. Nada "mais do mesmo" que justificar o enfrentamento das "crises" do sistema capitalista por meio de ajustes e retirada de direitos da classe trabalhadora, escondendo que a metade do orçamento geral da União é mobilizado para o pagamento de juros e amortização da dívida pública e que o processo de contrarreforma tinha como ponto central a expansão dos fundos de pensão para alimentar a roda-gigante do capital financeiro especulativo (Marconsin e Santos, 2008).

O governo Lula continuou a executar a reestruturação restritiva dos direitos previdenciários, atingindo em especial os servidores públicos, ao pôr fim à integralidade e ao impor limites dos benefícios ao teto do Regime Geral de Previdência Social (RGPS), dando abertura para a atuação no mercado dos fundos de previdência privada. A imposição de um limite máximo de aposentadoria induziu milhões de pessoas a buscarem na previdência privada uma possibilidade de manter condições dignas de vida (Rocha, 2016).

A transição do governo Lula para o governo Dilma deu continuidade à política econômica e social que se baseava principalmente no estímulo por parte do Estado brasileiro à formação de grandes oligopólios, comandados por expressivos grupos econômicos nacionais e internacionais privados que passam a controlar e regular a esfera econômica e política, assim como a continuidade 
dos programas de transferência de renda de cariz estatal que buscavam incentivar o consumo interno, por meio, entre outros, da elevação do salário mínimo e da expansão do Programa Bolsa Família.

No entanto, a agudização da crise capitalista internacional iniciada em 2008, sentida principalmente nos dois últimos anos do governo Lula, vai se materializar no governo Dilma na crise de hegemonia do projeto democrático-popular implementado pelos governos petistas, havendo um processo de reordenação do bloco do poder intensificado nas ranhuras pela hegemonia de parcela do capital creditício-financeiro; de commodities e da burguesia industrial nacional.

Outro elemento que impacta no esgotamento do pacto de conciliação de classes é a continuação das políticas macroeconômicas, advindas dos governos FHC e Lula, e que encontrarão seus limites no cenário de crise capitalista, dificultando a relação aparentemente harmoniosa entre as políticas de enfrentamento à extrema pobreza e o atendimento às necessidades do bloco hegemônico de poder, paralisando qualquer perspectiva de "crescimento" e "desenvolvimento" da economia do país. Diante da agudização da crise capitalista, o governo Dilma não hesitou em aprovar leis que feriram de morte o orçamento da Seguridade Social, em especial no âmbito da Previdência Social, dando continuidade ao processo de contrarreforma de seu antecessor (Teixeira e Pinto, 2012).

Na surdina da noite, o governo Dilma, em dezembro de 2014, editou medidas provisórias que posteriormente viraram leis e que tinham como elementos centrais a redução da aquisição de direitos ofertados pela previdência pública, assim como a diminuição e a restrição dos recursos de benefícios, num total ataque àqueles que mais dependem dessa política, no caso, dos(as) trabalhadores(as), sinalizando de alguma maneira a "necessidade" de se alterar a idade mínima para aposentadoria com modificações nas regras para trabalhadores(as) rurais e pensão por morte, o que está sendo efetivado pelo seu sucessor.

O governo Dilma se viu diante de um cenário caótico de estagnação econômica, com crescentes gastos governamentais e falta de controle das taxas de inflação impostas pelo próprio governo, indicando um quadro de possível recessão. Esse contexto de instabilidade possibilitou a efetivação do golpe jurídico-parlamentar que alterou a base de sustentação do governo Dilma e permitiu a ascensão do governo ultrarreacionário e ilegítimo de Michel Temer, 
em uma ampla coalizão que assegurou a intervenção econômica por meio de um duro plano de austeridade.

Ainda no apagar das luzes, o agonizante governo Dilma apresentou fôlego ao propor a Emenda Constitucional n. 87/15 que prorroga a Desvinculação das Receitas da União (DRU) até 2023 e amplia de $20 \%$ para $30 \%$ o percentual a ser desvinculado, o que possibilitou o desinvestimento de $30 \%$ na área da Seguridade Social, representando a retirada de cerca de R \$ 120 bilhões que irão "minimizar" o aumento e a expansão da dívida pública, numa reprodução do ideário neoliberal que prevê a resolução das "crises" do sistema capitalista por meio dos cortes em gastos sociais e redução de investimentos em serviços públicos essenciais (Gentil, 2017).

Tanto os governos Lula e Dilma quanto o governo ilegítimo de Temer não se preocuparam em "cortar na carne" os direitos históricos da classe trabalhadora para garantir os lucros do sistema financeiro e das elites burguesas. No entanto, é no governo Temer que se percebe uma aceleração dos desmontes de todo o sistema protetivo do trabalho, como meio de atender aos interesses dos organismos internacionais e dos grandes oligopólios nacionais e internacionais, materializado pelo conjunto de projetos de lei e emendas constitucionais para garantir os compromissos assumidos com o capital financeiro. A lógica simples, mas absolutamente perversa, demonstrou a impossibilidade de continuação do projeto de conciliação de classes emergente nos governos petistas, que ora mantinha os históricos privilégios da burguesia nacional e internacional, ora investia em políticas compensatórias para os(as) trabalhadores(as). Parece que o governo "esqueceu-se" somente de lembrar que, sob essa lógica, as elites capitalistas buscam a todo momento criar condições materiais e ideológicas de retomar o poder por meio de seus representantes legítimos.

É interessante notar que em todos esses governos a Seguridade Social é um campo de tensões e disputas entre capital e trabalho. Um dos fatores prejudiciais no entendimento do orçamento da Seguridade Social, em um cenário de "crise" capitalista e de austeridade fiscal, é o artifício e a falácia do superávit primário, e não o déficit previdenciário, vigente desde o acordo realizado em 1999 com o Fundo Monetário Internacional (FMI). Ao longo dos anos, percebe-se que o volume de alocação de recursos direcionados para a formação do superávit 
primário tem crescido, se comparado com os investimentos realizados no campo da Seguridade Social, especificamente nas áreas da Saúde e Assistência Social (Behring, 2008).

É preciso entender ainda que o financiamento da Seguridade Social está diretamente ligado ao mecanismo de alocação do fundo público, na medida em que este é alvo de disputa e de interesses entre as classes sociais antagônicas, operando ativamente nas políticas macroeconômicas, seja por meio da acumulação produtiva, seja por meio da esfera das políticas sociais, tendo assim função significativa tanto na continuidade do sistema capitalista quanto na preservação e cumprimento do contrato social, já que parte do fundo público serve para a ampliação das políticas sociais, garantindo o crescimento do consumo e do produtivismo, via programas de transferência de renda, e outra parte visa subsidiar e dar suporte às políticas anticíclicas em períodos de estagnação econômica (Salvador, 2010).

Sobre a disputa e o papel do fundo público no capitalismo contemporâneo, vale ressaltar que

o fundo público, tencionado pela contradição entre socialização da produção e apropriação privada do produto do trabalho social, atua realizando uma punção de parcela da mais-valia socialmente produzida para sustentar, num processo dialético, a reprodução da força de trabalho e do capital, socializando custos da produção e agilizando os processos de realização da mais-valia, base da taxa de lucros. (Behring, 2008, p. 55)

Para enfrentar a crise capitalista, que para Mandel (1990), além de ser uma crise de superprodução ou subconsumo, apresenta, entre outras dimensões importantes, a queda tendencial na taxa de lucros e o crescimento da composição orgânica do capital, o Estado brasileiro tem se utilizado do fundo público para salvaguardar os interesses do capital sobre o trabalho, reduzindo cada vez mais os custos deste e dos serviços públicos. Emprega-o ainda para socorrer corporações financeiras que se encontram colapsadas e arruinadas, por meio de subsídios, renúncias e evasões fiscais e pelo aumento de contribuições e impostos retirados da classe trabalhadora por intermédio da estrutura tributária regressiva, ou seja, quanto menos se ganha mais se paga (Salvador, 2010). 


\section{0 governo Temer e a aplicação do receituário neoliberal: vimos emergir o monstro da lagoa}

Essa política de "assalto" ao fundo público, aprofundada nos últimos governos, se radicaliza e se acelera consideravelmente no governo Temer. Sua função primordial é promover um "choque" de medidas neoliberais radicais de natureza conservadora e reacionária, que inclui um pacote que compromete sobremaneira o sistema protetivo garantido na Constituição Federal de 1988, entre eles a limitação dos gastos públicos em vinte anos; a desvinculação das pensões e aposentadorias das correções do salário mínimo; o desmonte da CLT e a lei de regulamentação da terceirização irrestrita. Em síntese, vemos de forma trágica o desmonte do Estado brasileiro, por meio da imposição de uma agenda neoliberal de cunho radical, que pretende, em curto tempo, alterar substancialmente as conquistas sociais tidas como privilégios, presentes na Constituição Federal de 1988.

Tais ataques demonstram em alguma medida a reorganização do capital financeiro e sua hegemonia, impondo à classe trabalhadora um cenário de extrema degradação humana, precarização e barbárie social, na medida em que restringe a competência do Estado em implementar políticas sociais que venham garantir a reprodução social da classe trabalhadora, assim como, em um único "tiro de misericórdia", fragmenta e esfacela a espinha dorsal da sua organização e de seus instrumentos históricos de resistência, como partidos, sindicatos e movimentos sociais.

No mesmo dia de sua posse, Temer edita a Medida Provisória n. 726/2016, transformada na Lei n. 13.341, que dispõe sobre a reestruturação da presidência da República e dos ministérios. No que se refere diretamente à Seguridade Social, ocorreram significativas alterações, entre elas: a extinção do Ministério da Previdência Social, sendo o INSS transferido para o novo Ministério do Desenvolvimento Social e Agrário; a transferência da Superintendência Nacional de Previdência Complementar - Previc e da Empresa de Tecnologia e Informações da Previdência Social - Dataprev para o Ministério da Fazenda, sob o comando do ministro Henrique Meirelles, ex-presidente do Banco Central nos dois mandatos do governo Lula e representante legítimo do capital financeiro, evidenciando a subsunção dos direitos sociais da maioria da população aos 
interesses do grande capital. É nesse governo que a ferocidade do capital se expressa com maior avidez e ódio de classe!

No contexto de crise do capital e tendência de mercantilização da vida social, acirrou-se o "assalto" ao fundo público, tendo como "nicho de mercado" especialmente a Saúde, a Previdência Social e a Educação. Sendo alvo prioritário, as políticas de Seguridade Social "são determinadas por um conjunto de necessidades que nascem no mundo da produção stricto sensu, mas não encerram ali o seu sentido" (Mota, 1995, p. 137).

A tese da autora, defendida em 1995, depois de mais de vinte anos, se mostra absolutamente atual no movimento da realidade brasileira. Segundo Mota (1995), concretizou-se nos anos 1990 a tendência de privatização da Previdência Social e da Saúde, acompanhadas da expansão da política de assistência social, favorecendo, em certa medida, a mercantilização dos serviços sociais, por meio, entre outros, da ampliação dos seguros-saúde e planos de previdência privada nesse período.

Recentemente ampliou-se o campo de ação da Assistência Social, via programas de transferência de renda, ao mesmo tempo em que se limitou o acesso à saúde e à Previdência Social com o objetivo de sua mercantilização.

Analistas são unânimes em afirmar que no Brasil a Seguridade Social não se traduziu na universalização do acesso aos benefícios sociais (Mota, 2007; Bravo, 2007; Boschetti e Salvador, 2007). Pelo contrário, podemos dizer que uma das estratégias presentes na "nova" gestão estatal da força de trabalho é incorporar o processo de precarização como inevitável, a mercantilização como fato inexorável e a subordinação do público ao privado como iniciativas complementares e parte constitutiva das novas experiências de gestão (Mota, 2007, p. 43).

Segundo a autora, a resultante desse processo é a transformação em "cidadãos consumidores" daqueles que serão forçados a "comprar" no mercado os serviços mercantilizados e em "cidadãos pobres" aqueles que, pela sua condição, não têm como pagar os serviços logo, são "merecedores" da política de assistência social. Constata-se que "a previdência e a assistência sociais passaram a constituir uma unidade contraditória (a negação de um sistema único de previdência social pública é, ao mesmo tempo, a base para afirmação de um sistema único de assistência social)...” (Mota, 2007, p. 44). 
A tendência de focalização e desfinanciamento das políticas de Seguridade Social evidenciaram-se com maior intensidade na política de assistência social enquanto objeto de ações e programas de combate à pobreza, à moda dos organismos financeiros internacionais. A centralidade dos programas de transferência de renda, em detrimento da efetivação do SUAS e financiamento de serviços continuados, evidencia a subordinação à lógica econômica.

\section{Desafios (im)postos ao Serviço Social: atordoado eu permaneço atento!}

É nesse contexto regressivo, de ataques do "neoliberalismo tardio", que as políticas sociais vão sendo refuncionalizadas ao limite de se constituírem, como alerta Vieira (1997) em políticas sociais sem direitos sociais, e é nesse cenário que os(as) assistentes sociais realizam sua intervenção profissional e constroem respostas profissionais. Ao longo dos últimos trinta anos, a consciência de pertencimento à classe trabalhadora e vinculação a esse projeto societário tem sido a direção social assumida pela categoria, expressa concretamente nos espaços coletivos, cujo marco histórico foi o III Congresso Brasileiro de Assistentes Sociais - CBAS (1979), e ao mesmo tempo na retomada e direção dos órgãos representativos. A agenda política da categoria tem expressado ao longo desses anos o compromisso ético-político com as lutas da classe trabalhadora, revelando a direção social assumida pelo Serviço Social.

Os Encontros Nacionais do Conjunto CFESS/CRESS são o fórum máximo de deliberação da categoria, expressando-se num espaço de debate representativo e democrático. Particularmente, no $29^{\circ}$ Encontro Nacional, realizado de 3 a 6 de setembro de 2000, na cidade de Maceió (AL), a categoria deliberou por fazer a luta em defesa da Seguridade Social no país aprovando o documento "Carta de Maceió - Seguridade Social pública: é possível!".

Ao longo dos últimos anos, esse documento tem sido referência estratégica na concepção ampliada de Seguridade Social, bem como no caráter crítico e propositivo de seu conteúdo, proporcionando unidade política e programática para as ações individuais e coletivas dos(as) assistentes sociais no país.

As determinações do atual momento de crise do capital agravam as condições e relações de trabalho dos(as) assistentes sociais tanto nos seus impactos 
sobre as respectivas políticas nas quais realiza sua intervenção quanto nas condições objetivas como trabalhador(a).

Nesse contexto de refluxo de direitos trabalhistas, a redução da jornada de trabalho para trinta horas semanais sem redução de salários em 2010 expressou uma conquista para os(as) assistentes sociais, submetidos em seu cotidiano profissional, juntamente com demais trabalhadores(as), a intensos processos de precarização do trabalho.

No âmbito da política de saúde, os(as) assistentes sociais têm tido seu cotidiano profissional substancialmente alterado por conta dos processos de privatização realizados pelas Oscips, O.S, Fundações, EBSERH, dentre outras, precarizando ainda mais seus vínculos empregatícios, soterrando cada vez mais o projeto de reforma sanitária. A proposta do atual Ministério da Saúde de criação de "planos de saúde acessíveis" segue a lógica da fragmentação do sistema e ampliação da privatização da saúde.

Com o objetivo de exigir a implementação do Sistema Único de Saúde - SUS com base nos princípios da reforma sanitária e fazer o enfrentamente ao seu desmonte foi criada a Frente Nacional contra a Privatização da Saúde. Sendo instância de representação e militância na área, como trabalhadores(as) da saúde, esse espaço tem mobilizado a participação de assistentes sociais no país, construindo unidade política e ação estratégica, particularmente nos espaços das conferências de saúde.

No que se refere à política de Assistência Social, os últimos anos foram marcados pela profissionalização na área, ampliando-se o mercado de trabalho através de concursos públicos especialmente no âmbito municipal, com a implementação do Sistema Único de Assistência Social — SUAS através das unidades estatais: os Centros de Referência Especializada de Assistência Social - CRAS e os Centros de Referência Especializada de Assistência Social CREAS. Porém essa área tem se revelado como o espaço com maior precarização das relações e condições de trabalho, bem como vínculos instáveis e menores salários, expressando-se também no baixo grau de organização e mobilização política desses(as) trabalhadores(as).

O aumento do primeiro-damismo, identificado tanto nas gestões municipais, estaduais, quanto seu retorno no atual governo ilegítimo de Temer, evidencia 
a fragilidade do reconhecimento da primazia da responsabilidade do Estado na sua condução como política de direito no âmbito da Seguridade Social.

Fruto de uma recente mobilização do coletivo de trabalhadores(as), em 2011 foi criado o Fórum Nacional de Trabalhadores(as) do Sistema Único de Assistência Social - FNTSUAS, espaço de articulação e pressão política tanto na defesa da política como direito social quanto no reconhecimento dos direitos como trabalhadores(as).

Sendo recente, tanto estados quanto municípios têm criado esse espaço que se expressa como ambiente autônomo e representativo dos(as) trabalhadores(as) do Suas, entre estes os(as) assistentes sociais. Além da articulação na base para representação nos espaços públicos dos conselhos e conferências de Assistência Social, o FNTSUAS teve como estratégia a incidência sobre a definição da Mesa Nacional de Negociação e tem lutado para sua implementação a partir dos interesses dos(as) trabalhadores(as).

A política de Previdência Social como novo nicho de mercado tem sido a mais atacada, particularmente o Serviço Social. Não sendo uma política municipalizada, o maior empregador é o governo federal através do Instituto Nacional de Seguro Social - INSS, no qual o Serviço Social atua há 72 anos.

Depois de intensas mobilizações, o quadro de profissionais foi renovado com a realização de concursos públicos a partir de 2009, sendo atualmente o espaço, no âmbito da Seguridade Social, que se reflete em maior estabilidade e maiores salários para os(as) assistentes sociais. Porém, na esfera do INSS, os sistemáticos ataques à autonomia profissional, bem como às atribuições e competências profissionais, têm exigido a mobilização da categoria que, além de lutar pelas prerrogativas profissionais, tem se mobilizado com os(as) demais trabalhadores(as) contra a PEC n. 241/2016, que é um verdadeiro processo de contrarreforma da Previdência Social.

O desmonte do Benefício de Prestação Continuada - BPC proposto por essa PEC, aumentando a idade de acesso de 65 (sessenta e cinco) para 70 (setenta), juntamente com a desvinculação do valor do salário mínimo, expressa a derruição de direitos conquistados que os(as) assistentes sociais historicamente têm defendido.

O avanço galopante do conservadorismo tende a produzir "novas velhas" requisições que visam ameaçar as conquistas expressas tanto na lei de 
regulamentação da profissão quanto no Código de Ética Profissional, em especial no que tange às competências e atribuições, na medida em que impõe um processo de desprofissionalização das políticas sociais, por meio do retorno ao assistencialismo, solidariedade indiferenciada, voluntariado e a prestação da ajuda de forma altruísta, explícito, entre outros, no programa Criança Feliz.

No reino da fantasia de "ordem e progresso" do governo Temer prevê-se o desmonte completo do Sistema Único de Assistência Social (SUAS) e sua transferência para as ações pulverizadas filantrópicas e clientelistas, em que o reino da "boa vontade" parece imperar e garantir algum sopro de vida para a classe trabalhadora.

Diante desse cenário de "lama e caos", como nos lembra o saudoso Chico Science, o que nos resta é nos organizar coletivamente, seja nos espaços da categoria (conjunto CFESS/CRESS/ABEPSS/ENESSO), seja por dentro das políticas (fóruns e frentes) ou ainda nos espaços sindicais e partidários. A única saída viável deve se dar por meio dos espaços de militância coletiva, já que "me organizando posso desorganizar e desorganizando posso me organizar", cujo objetivo maior deve ser a derruição de todas as formas de exploração e opressão, onde nosso corpo, ainda humano, não seja submetido a uma velocidade e intensidade de vida desumana.

O momento exige da classe trabalhadora unidade política fundada na análise crítica e autocrítica. Como trabalhadores(as), os(as) assistentes sociais, assumindo seu protagonismo de classe, são instados a participar e aliar-se às lutas sociais mais amplas que expressem a "opção por um projeto profissional vinculado ao processo de construção de uma nova ordem societária, sem dominação, exploração de classe, etnia e gênero" (CFESS, 2011, p. 24).

Até aqui houve luta e resistência, capacidade intelectual e analítica, compromisso ético-político e ação organizada para construir o Serviço Social como profissão relevante na sociedade brasileira.

Para enfrentar os desafios da atual conjuntura, o futuro exige no presente "mais vontade política organizada e menos ilusões otimistas" (Netto, 2007, p. 40).

Recebido em 24/4/2017 - Aprovado em 13/6/2017 


\section{Referências bibliográficas}

ALVES, Giovanni. Trabalho e desenvolvimento: choque de capitalismo e nova degradação do trabalho no Brasil. Bauru: Canal 6, 2014.

. Dimensões da precarização do trabalho: ensaios de sociologia do trabalho. Bauru: Canal 6, 2013.

. Nova ofensiva do capital, crise do sindicalismo e as perspectivas do trabalho - O Brasil nos anos noventa. In: TEIXEIRA, Francisco J. S. et al. Neoliberalismo e reestruturação produtiva: as novas determinações do mundo do trabalho. São Paulo: Cortez; Fortaleza: Universidade Estadual do Ceará, 1996.

BEHRING, Elaine R. Acumulação capitalista, fundo público e política social. In: BOSCHETTI, Ivanete et al. Política social no capitalismo: tendências contemporâneas. São Paulo: Cortez, 2008.

- Brasil em contrarreforma: desestruturação do Estado e perda de direitos. São Paulo: Cortez, 2003.

BOSCHETTI, Ivanete; SALVADOR, Evilásio. O financiamento da Seguridade Social no Brasil no período 1999 a 2004: quem paga a conta? In: MOTA, Ana Elizabete Simões da et al. Serviço Social e saúde: formação e trabalho profissional. 2. ed. São Paulo: Cortez, Opas, OMS, Ministério da Saúde, 2007. p. 49-72.

BRAVO, Maria Inês Souza. Política de saúde no Brasil. In: MOTA, Ana Elizabete Simões da et al. Serviço Social e saúde: formação e trabalho profissional. 2. ed. São Paulo: Cortez, Opas, OMS, Ministério da Saúde, 2007. p. 88-110.

BRESSER-PEREIRA, L. C. A reforma do estado dos anos 90. Cadernos Mare, n. 1, Brasília, 1997.

. Desenvolvimento e crise no Brasil: 1930 - 1967. 1. ed. Rio de Janeiro: Zahar Editores, 1968.

CASTELO, Rodrigo. O novo-desenvolvimentismo e a decadência ideológica do estruturalismo latino-americano. In: . (Org.). Encruzilhadas da América Latina no século XXI. Rio de Janeiro: Pão e Rosas, 2010.

. O novo desenvolvimentismo e a decadência do pensamento econômico brasileiro. Serviço Social \& Sociedade, São Paulo, n. 112, p. 613-636, out./dez. 2012. 
CONSELHO FEDERAL DE SERVIÇO SOCIAL. Resolução CFESS n. 273, de 13 de março de 1993. In: . Código de Ética Profissional do/a Assistente Social. 9. ed. revista e atualizada. Brasília: CFESS, 2011.

FATORELLI, Maria Lúcia. Entrevista. Disponível em: <http://www.auditoriacidada. org.br/blog/2016/03/17/entrevista-com-maria-lucia-fattorelli-a-contrarreforma-daprevidencia/>. Acesso em: 18 abr. 2017.

GENTIL, Denise. Reforma da Previdência: incoerência ou estratégia? Boletim da ADUFRJ, ano II, n. 72.13 abr. 2017. Disponível em: < http://www.adufrj.org.br/images/ boletim\%2072_eletr\%C3\%B4nico\%202.pdf>. Acesso em: 15 abr. 2017.

IAMAMOTO, Marilda V. Classes trabalhadoras e política social no Brasil. In: BOSCHETTI, Ivanete et al. Política social no capitalismo: tendências contemporâneas. São Paulo: Cortez, 2008, p. 13-43.

. O Serviço Social na contemporaneidade: trabalho e formação profissional. São Paulo: Cortez, 1998.

MANDEL, Ernest. A crise do capital: os fatos e sua interpretação marxista. São Paulo: Ensaios, 1990.

MARCONSIN, Cleir; SANTOS, Cleusa. A acumulação capitalista e os direitos do trabalho: contradição histórica que preside a Seguridade Social. In: BEHRING, Elaine; ALMEIDA, Maria Helena Tenorio de. Trabalho e Seguridade Social: percurso e dilemas. São Paulo: Cortez; Rio de Janeiro: FSS/Uerj, 2008. p. 175-192.

MARX, K. O capital: crítica da economia política. Livro III: O processo global da produção capitalista. São Paulo: Boitempo, 2017.

MONTAÑO, Carlos; DURIGUETTO, Maria Lúcia. Estado, classe e movimento social. 3. ed. São Paulo: Cortez, 2011.

MOTA, Ana Elizabete. Cultura da crise e Seguridade Social. São Paulo: Cortez, 1995. Serviço Social e Seguridade Social: uma agenda recorrente e desafiante. Em Pauta: Teoria Social \& Realidade Contemporânea. Rio de Janeiro, n. 20, p. 127-138, 2007.

NETTO, José Paulo. Das ameaças à crise. Inscrita, Brasília, n. 10, p. 37-40, nov. 2007.

OLIVEIRA, Ednéia Alves de. A política de emprego no Brasil: o caminho da flexisegurança. Serviço Social \& Sociedade. São Paulo, n. 111, p. 493-508, jul./set. 2012. 
ROCHA, Flávia R. F. A disputa do fundo público da Previdência Social no contexto da mundialização do capital. Revista de Políticas Públicas [on-line], v. 20, p. 473-492, 2016. Disponível em: <http://www.redalyc.org/articulo.oa?id=321149853004>. Acesso em:15 abr. 2017.

SALVADOR, Evilásio. Fundo público e Seguridade Social no Brasil. São Paulo: Cortez, 2010.

TEIXEIRA, Rodrigo Alves; PINTO, Eduardo Carlos. A economia política dos governos FHC, Lula e Dilma: dominância financeira, bloco no poder e desenvolvimento econômico. Economia e Sociedade, Campinas, v. 21, Número Especial, p. 909-941, dez. 2012. Disponível em: <file://C:/Users/esthe/Downloads/8642267-13761-1-SM. pdf>. Acesso em: 15 abr. 2017.

VIEIRA, Evaldo Amaro. As políticas sociais e os direitos sociais no Brasil: avanços e retrocessos. Serviço Social \& Sociedade, São Paulo, n. 53, p. 67-73, mar. 1997. 